\title{
Does Consciousness Exist Independently of Present Time and Present Time Independently of Consciousness?
}

\author{
Birgitta Dresp-Langley, Jean Durup \\ Centre National de la Recherche Scientifique Unité Mixte de Recherche, Montpellier, France \\ Email: Birgitta.Dresp-Langley@univ-montp2.fr
}

Received November $20^{\text {th }}, 2011$; revised December $28^{\text {th }}, 2011$; accepted January $5^{\text {th }}, 2012$

\begin{abstract}
While some are currently debating whether time may or may not be an illusion, others keep devoting their time to the science of consciousness. Time as such may be seen as a physical or a subjective variable, and the limitations in our capacity of perceiving and analyzing temporal order and change in physical events definitely constrain our understanding of consciousness which, in return, constrains our conceptual understanding of time. Temporal codes generated in the brain have been considered as the key to insight into neural function and, ultimately, as potential neural substrates of consciousness itself. On the basis of current evidence and opinion from neuroscience and philosophy, we consider the interrelation between consciousness and time in the light of Hegel and Heidegger's concepts of Sein (Being) and Zeit (Time). We suggest that consciousness can be defined in terms of a succession of psychological moments where we realize that we exist in, and are part of, a present moment in time. This definition places all other perceptual or sensorial processes which may characterize phenomenal experience at a different level of analysis and centers the debate around consciousness on the fundamental identity link between awareness of the Ich (I) and awareness of what Heidegger termed Ursprüngliche Zeit (original time). We argue that human consciousness has evolved from the ability to be aware of, to remember, and to predict temporal order and change in nature, and that the limits of this capacity are determined by limits in the functional plasticity of resonant brain mechanisms. Although the conscious state of the Self is the ultimate expression of this evolution, it is devoid of any adaptive function as such.
\end{abstract}

Keywords: Consciousness; Time; Temporal Order; Awareness of Self

\section{Introduction}

Lloyd (2004) suggested that once we understand temporality, possible ways of understanding the complex workings of consciousness may open before us. During early childhood, our brains learn about temporal and spatial order of the physical world, well before we become phenomenally conscious of a Self and its immediate or distant environment (Piaget, 1967). Current research in behavioral neuroscience indicates that statistical learning of temporal regularities in sensory input is the first way through which humans and animals acquire knowledge of physical reality and the structure of continuous sensory environments. This form of non-conscious learning of the temporal frequency of physical events exists in different species and was recently found to be present at birth in humans on the basis of experiments where newborns were exposed to and tested with speech stream inputs (Bulf, Johnson, \& Valenza, 2011). Phenomenal experience, conscious knowledge representtation, and abstract reasoning have occurred relatively late in evolution. They reflect a mental capacity that develops ontogenetically in the first two to three years of an individual's lifespan (Jaynes, 1990; Edelman, 1993). To explain how physical information is represented and processed in the brain for learning and, ultimately, conscious experience, neuroscientists have tried to decipher structural properties of brain activity patterns. This has produced theoretical models which link consciousness to temporal properties of neural circuits (Helekar, 1999; DrespLangley \& Durup, 2009; Fingelkurts, Fingelkurts, \& Neves, 2010).
Consciousness reflects the highest capacity level of the brain to link space and time within global mental representations (Smythies, 2003). Temporal order is possibly the most important aspect in this linking process, and once consciousness is fully operational, it is constrained by temporal factors only. Consciousness may express itself as the reflection of a specific brain state, the conscious state (John, 2002). It enables humans to weigh and compare mental events relating to past, present, and future, in one and the same moment of time, which we call present time. At this specific instance, time appears to come to a halt while the conscious mind is busy assessing and taking stock of data and events. Moreover, although sensations may be necessary for perceptual experience, the experiential presence of a particular environmental property or object does not necessarily involve corresponding sensations (Natsoulas, 1999). Conscious moments therefore require temporal not spatial permanency. The following three postulates will be considered to take this essay on the ontological links between consciousness and temporality further:

1) If mankind were to disappear tomorrow and no other conscious species exists in the universe, present time as we conceive it would also disappear; what remains of nature and physical reality will continue to be subject to some form of order and relativity.

2) Measures of time used in science describe arbitrary forms of scaling biophysical time, accounting for the temporal order of events that we observe in nature and physics.

3) What some have called "mind-phenomenal" and others 
"psychological" time corresponds to a subjective form of scaling that is not part of objective or physical reality.

\section{Brain Operations in Biophysical Time}

Brain activity is measured in terms of firing activity recorded in biophysical time, sometimes described in terms of periods or epochs. These latter, specific or non-specific, are characterized by variations in the amplitude and temporal frequency of electric signals emitted by single neurons or groups of neurons. Electric activity patterns of neurons and circuits in the human brain appear to have some form of spatial and temporal organization, which can be observed with greater or lesser precision depending on currently available technology (Von Stein et al., 2000, Palva et al., 2005, 2007; Başar, 2006, Axmacher et al., 2006, 2010; Canolty et al., 2006, 2010; Jacobs et al., 2007). The characteristics of such functional organization have been linked to specific brain operations within limited space-time frames (Engel \& Singer, 2001, Rees et al., 2002, Crick \& Koch, 2003, Libet, 2004, Melloni et al., 2007, Singer, 2009, Mathewson et al., 2009, Lisman, 2010, Fingelkurts et al., 2010), enabling the execution of complex cognitive activities such as reading, analytical reasoning, creative thinking, volition and guided motor control (e.g. Rosenthal, 2008). However, most of our sensations and perceptions are processed implicitly by the brain, and truly conscious states seem to be reflected by short oscillatory activity periods of not more than a few hundreds of milliseconds each (Buzsáki, 2007, Luo \& Poeppel, 2007, Del Cul et al., 2009, Droege, 2009, Forget et al., 2010). The clockworks of consciousness may thus be conceived in terms of rapid temporal successions of microscopic brain states (Helekar, 1999), and it has been suggested that such temporal mechanisms would be capable of generating epigenetically determined activity patterns which constitute the code through which consciousness may be encrypted in the brain (Dresp-Langley \& Durup, 2009).

Consciousness enables the subjective recollection or experience of mental events relating to the past, present, or future at a given moment in time. The resource limits of a conscious moment (Cowan, 2001) may be identified with those of working memory (Amiez \& Petrides, 2007), which can be seen as a brain processing state where short-term and long-term memory representations coincide and interact (Hermann et al., 2004, Jonides et al., 2008, Holz et al., 2010). Conscious brain processing has been associated with resonant neural mechanisms (Grossberg, 1999, Maia \& Cleeremans, 2005, Lamme, 2006) that stabilize over a time scale of no more than a few hundred milliseconds (Taylor, 1998, Grossberg, 1999, Herzog et al., 2007), according to the biophysical clockworks of conscious brain activity. Sound signals, for example, are processed by cortical neurons in less than half a second, and our brain is able to compare a first signal pattern to a second in order to determine how much time has elapsed between the two. Long periods of time may be analyzed by the brain in terms of pulses (Buhusi \& Meck, 2009) and in similar ways as rhythm or music. It is, however, still not known how brain regions are able to record and understand time. Reading sense into the brain's signalling is one thing, understanding how its neural networks generate memories from such signalling requires additional forms of knowledge.

Brain processing has much to do with attributing temporal order to objects and events, which may or may not be present together at the same moment in time, and which may or may not do so in the future. The notion of temporal periods and event succession is accessible to non-human animals, and helps them to find, in the right order, food items they had hidden in successive locations weeks ago. The specifically human ability to be conscious of a Self that exists at a moment of present time raises the question of the place this ability takes across evolution, and its possible adaptive role. It was recently shown by Nyberg et al. (2010) that specific brain areas are activated when a person's mind travels into past or future (chronesthesia), as compared to focusing on the present moment, and the mind's ability to travel in time is well known to be impeded by various forms of amnesia. It is not known, however, whether from an evolutionary viewpoint the capacity of representing past or future is more or less recent than that of being conscious of present time. While the former is likely to be operational in species other than man, such as non-human primates, the latter is almost certainly characteristic of humans only, who are capable of communicating conscious experience of Self and present time to each other through language or, more precisely, the spoken word. While any animal would gain a definite evolutionary advantage from being able to follow the temporal course of physical events for the priming of adaptive behaviour and action, no particular moment in time stands out as the present moment (here and now) in such ability. The fact that the human conscious mind is able to realize its own existence in a changing world (I am part of what happens right now), which also defines any present moment of the Universe, does not increase human capacity to act on either the world or the Self. Although this suggests that consciousness may be devoid of any adaptive function, only very few authors (e.g. Pockett, 2004) have considered such a possibility.

\section{Mind Phenomenal or Psychological Time}

The relative temporal permanency of existence in space or time is different from what we may call "psychological time" (Dresp-Langley \& Durup, 2009), or what Fingelkurts et al. (2010) have called "mind-phenomenal time". Psychological time relates to what our conscious minds perceive in terms of long or brief events, sometimes experienced in terms of boring or exciting. Such inner clockworks may not bear any relation with physical reality and need to be distinguished from the clockworks of biophysical time. The philosopher David Hume in his Treatise of Human Nature (1740) described events in psychological time in terms of a flux of scenes passing by, or coming and going. Thus, phenomenal consciousness appears to continually move from one relatively stable representation to another, yet, we experience such movement in terms of a single moment in present time, the here and now. The subjective sense of present time is the temporal framework in which all experience takes place (cf. Grush, 2005). If one of the major functions of consciousness is, indeed, that of ordering events into temporal sequences (Seth et al., 2006), taking stock, and assessing the meaning and significance of what is happening both within and outside the mind at a given moment in time, then a scientific understanding of the relationship between time and mind depends on our ability to explain how the scaling of phenomenal time can be linked to that of biophysical time.

Observations of experience-related neural timing patterns (Johnson \& Buonomano, 2010, Nyberg et al., 2010) suggest that there may be ways of linking psychological to biophysical time, but too little is still known about functional implications. 
Our conscious perception of time can definitely mislead us, as demonstrated by the well-known Kappa effect, where the duration of two successive stimulations is perceived longer when the two sources of stimulation are closer in space (e.g. Sarrazin et al., 2007). The only characteristic of temporality that the human mind is able to asses spontaneously and with certainty is that of present time and consciousness, although private and hard to define, is intricately linked to a present state of the Universe.

\section{Mind and Time in the Philosophies of Kierkegaard, Hegel and Heidegger}

Man has used and studied the concept of time for 2500 years, yet, there are many issues regarding time that have remained unresolved (cf. Carroll, 2010). Physicists have developed precise temporal descriptions of the past of the Universe, and there is an amazing consistency between theory and a steadily growing amount of observations, yet, no physicist has ever defined what present time is. Questions about the nature of the difference between present, past and future are at the heart of current controversy in philosophy (Carroll, 2010). Some argue that only present objects and present experiences are real, and that conscious beings recognize this in the special "vividness" of their present experience. The past has already slipped out of reality. According to other viewpoints, both the past and present are real, but the future is not, it is only potential. The Gulf Wars are real, but our dying is not, for example. A current philosophical argument states that, if the future were real, then it would be fully determined in the here and now and we would have no freedom or power to shape that future, but since we do have that freedom and power, the future cannot be real. A third theory claims that there are no significant ontological differences between present, past, and future because our perception or appreciation of such differences, whether they exist or not, is purely subjective. Our minds tend to confuse mind time with the objective biophysical clockworks, which must exist in nature and may be described in terms of observable, periodic or cyclic, events through some arbitrary measure. But which of the different, intuitive and culturally determined beliefs that exist about time or calendars should be considered? Intuitions about time and temporal order may well stem from some deeper insight into the nature of physical reality, or they may well not. This leads to the question of what physical science can actually teach us about time, and whether we can be sure that the instant we perceive as occurring at a specific time of our calendar year exists independently from the events that occur at that instant. In other words, does time exist if nothing is happening? We recognize time and direction as we do because we assume the one-directionality of all processes of nature, however, what actually constitutes the present, how long it lasts, and why exactly it moves into the past has not ever been accounted for scientifically. What we experience as the march of time may not be a property of physical reality at all, but merely a property of human consciousness (see, for example, the recent discussion by Callender, 2010), yet, most of us would probably firmly maintain that time flowing in a single direction is real, and must therefore exist objectively and independently from our perception.

The Danish philosopher Søren Kierkegaard (1849, 1949) conceived present time as a moment in which the mind is able to recognize its own finality, through which it inevitably seizes the full meaning of nothingness, and despairs. Kierkegaard's implicit assumption of some fundamental identity link between human consciousness, awareness of the Self and present time is also found in the philosophies of Hegel (1807) and Heidegger (1927). In his essays on the phenomenology of the mind (Phänomenologie des Geistes, 1807), Hegel discusses the identity link between time and a conscious observer, the conscious I (Ich), of states of being (Sein). In time only, which is something abstract and ideal, the conscious I conceives its own Being (das Sein) which, by being is not, and by being not is. In other words, time is the Becoming (das Werden), or the transition between Being and Nothingness (Nichts) and between Nothingness and Being, as seen by a conscious observer. The being of time itself, according to Hegel, is the here and now (das Hier und Jetzt). However, since each here and now is a transition between not yet and not anymore, it can also be conceived as Nothingness, meaning that the state of here and now may be regarded as either a state of pure being, or a state of pure nothingness. Interestingly, this way of conceiving the consciousness of Being, or the conscious I, also appears in Buddhism, where pure Being and pure Nothingness are one and the same thing. In his essays on time and being (Sein und Zeit) Heidegger elaborates on Hegel's theory of the identity link between time and consciousness, but with a different view of the nature of this link. Heidegger argues that present time (Gegenwart), or the pure now (das Jetzt), needs to be distinguished from what we may call the "moment" (der Augenblick), which Heidegger conceives in terms of an "ecstatic" phenomenon of the conscious mind projecting a present state of being towards some future state of being. Thereby, Heidegger does not see time as the transition between Being and Nothingness as seen by the conscious " $I$ ", but as a result of the temporality (Zeitlichkeit) of consciousness itself. In Heidegger's view, consciousness and now time (Jetzt Zeit), which he also calls natural time (ursprüngliche Zeit) are, indeed, one and the same thing.

To separate present time from some state of consciousness is, thus, impossible. This has important implications for current models of consciousness. The true state of the conscious $I$, identical with the present moment of time, should be separated from what is commonly called phenomenal consciousness, which describes a flux of perceptions, memories and thoughts invading the conscious mind. How the conscious $I$ would be related to all this phenomenal subjectivity is illustrated here in Figure 1. A direct consequence of the identity link between present time and a conscious state of being would be that all phenomenal reality including temporal reality inevitably originnates from this identity link, or as Heidegger writes "nur Jetzt-Zeit ist wirklich" (only now-time is real). However, as pointed out by Libet (2004), our subjective inner life is what really matters to us as human beings. How our conscious experience of temporality relates to the true temporal order that governs the universe is not known.

\section{Conclusion}

Before Kierkegaard, Hegel or Heidegger, Aristoteles wrote in his essays entitled Physis "Whether, if the soul did not exist, time would exist or not, is a question that may well be asked; for if there cannot be someone to count there cannot be anything to be counted... all depends on whether time is the conscious numbering of movements, or the possibility of movements being numbered where consciousness exists." When 


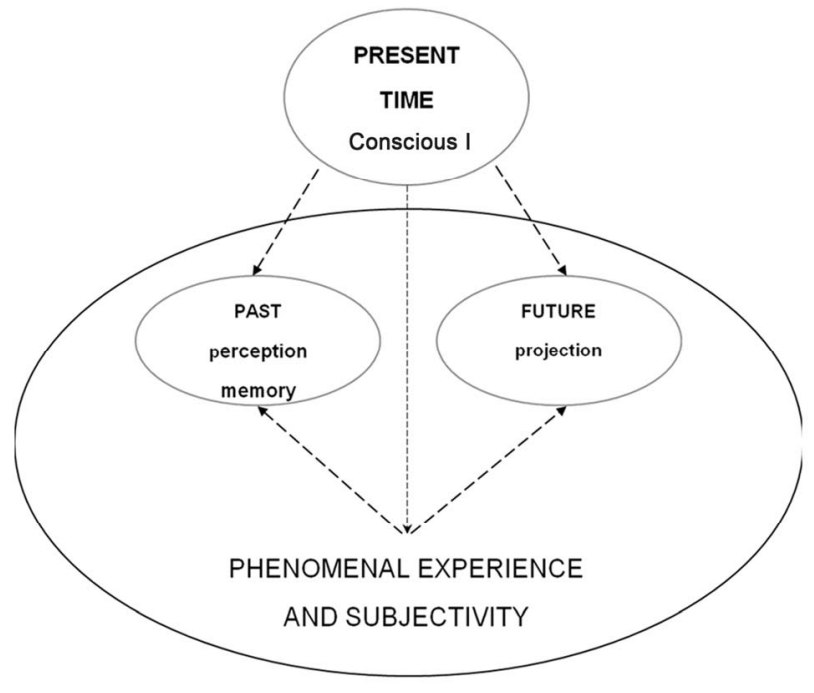

Figure 1.

All phenomenal reality originates from the identity link between present time and the conscious $I$. This leads to consider consciousness and specific cognitive abilities such as perception, memory or projective thinking or reasoning at separate ontological levels.

physicists investigate speed as the rate of change of the position of an object within some measure of time, they learn about events taking place in the physical world. When psychologists investigate memory as the number of items correctly recalled from a list within some measure of time, they learn about events taking place in the psychological world. Measures of time are the grounds upon which all science is built. Like consciousness itself, time places events. Time is to suggest the existence of order, and is therefore expressed in numbers. These numbers are given by regular oscillatory signal events, which behave like the regular ticking of a clock, and exist in many physical systems including the human brain. There can be no doubt that the mechanisms through which our brain performs a conscious analysis of temporal order and change originates from the neural connections which enable man to realize that he exists at this present moment of time. Man is hitherto the only species known capable of such realization.

\section{REFERENCES}

Amiez, C., \& Petrides, M. (2007). Selective involvment of the mid-dorsolateral prefrontal cortex in the coding of the serial order of visual stimuli in working memory. Proceedings of the National Academy of Sciences of the USA, 104, 13786-13791. doi:10.1073/pnas.0706220104

Axmacher, N., Mormann, F., Fernández, G., Elger, C. E., \& Fell, J. (2006). Memory formation by neural synchronization. Brain Research Reviews, 52, 470-482. doi:10.1016/j.brainresrev.2006.01.007

Axmacher, N., Henscher, M. M., Jensen, O., Weinreich, I., Elger, C. E., \& Fell, J. (2010). Cross-frequency coupling supports multi-item working memory in the human hippocampus. Proceedings of the National Academy of Sciences of the USA, 107, 3228-3233. doi:10.1073/pnas.0911531107

Başar, E. (2006). The theory of the whole-brain-work. International Journal of Psychophysiolog, 60, 133-138. doi:10.1016/j.ijpsycho.2005.12.007

Buhusi, C. V., \& Meck, W. H. (2009). Relative time sharing: New findings and an extension of the resource allocation model of temporal processing. Philosophical Transactions of the Royal Society Lon- don B, 364, 1875-1885. doi:10.1098/rstb.2009.0022

Bulf, H., Johnson, S. P., \& Valenza, E. (2011). Visual statistical learning in the newborn infant. Cognition, 121, 127-132. doi:10.1016/j.cognition.2011.06.010

Buzsáki, G. (2007). The structure of consciousness. Nature, 446, 267. doi: $10.1038 / 446267 \mathrm{a}$

Callender, C. (2010). Is time an illusion? Scientific American, 295, 58-65. doi:10.1038/scientificamerican0610-58

Canolty, R. T. et al. (2006). High gamma power is phase-locked to theta oscillations in the human neocortex. Science, 313, 1626-1628. doi: $10.1126 /$ science. 1128115

Canolty, R. T., \& Knight, R. T. (2010). The functional role of crossfrequency coupling. Trends in Cognitive Sciences, 14, 506-515. doi:10.1016/j.tics.2010.09.001

Carroll, S. (2010). From eternity to Here: The quest for the ultimate theory of time. New York: Dutton/Penguin Group.

Cowan, N. (2001). The magic number 4 in short-term memory: A reconsideration of mental storage capacity. Behavioural and Brain Science, 24, 87-114. doi:10.1017/S0140525X01003922

Crick, F., \& Koch, C. (2003). A framework for consciousness. Nature Neuroscience, 6, 119-126. doi:10.1038/nn0203-119

Damasio, A. R. (2002). Remembering when. Scientific American: Special Edition: A Matter of Time, 287, 3.

Del Cul, A., Dehaene, S., Reyes, P., Bravo, E., \& Slachevsky, A. (2009). Causal role of prefrontal cortex in the threshold for access to consciousness. Brain, 132, 2531-2540. doi:10.1093/brain/awp111

Drecke, L. (1990). Electrophysiological correlates of movement initiation. Revue Neurologique (Paris), 146, 612-619.

Dresp-Langley, B., \& Durup, J. (2009). A plastic temporal brain code for conscious state generation. Neural Plasticity, 2009, 482-696. doi: $10.1155 / 2009 / 482696$

Droege, P. (2009). Now or never: How consciousness represents time. Consciousness and Cognition, 18, 78-90. doi:10.1016/j.concog.2008.10.006

Edelman, G. M. (1993). Neural Darwinism: Selection and reentrant signaling in higher brain function. Neuron, 10, 115-125. doi:10.1016/0896-6273(93)90304-A

Engel, A. K., \& Singer, W. (2001). Temporal binding and the neural correlates of sensory awareness. Trends in Cognitive Sciences, 5, 16-25. doi:10.1016/S1364-6613(00)01568-0

Fingelkurts, A, Fingelkurts, A. A., \& Neves, C. F. H. (2010). Natural world physical, brain operational, and mind phenomenal space-time. Physics of Life Reviews, 7, 195-249. doi:10.1016/j.plrev.2010.04.001

Forget, J., Bulatti, M., \& Dehaene, S. (2010). Temporal integration in visual word recognition. Journal of Cognitive Neuroscience, 22, 1054-1068. doi:10.1162/jocn.2009.21300

Grossberg, S. (1999). The links between brain learning, attention, and consciousness. Consciousness and Cognition, 8, 1-44. doi:10.1006/cog. 1998.0372

Grush, R. (2005). Internal models and the construction of time: Generalizing from state estimation to trajectory estimation to address temporal features of perception, including temporal illusions. Journal of Neural Engineering, 2, 209-218. doi:10.1088/1741-2560/2/3/S05

Haggard P., Clarke S. (2003). Intentional action: Conscious experience and neural prediction. Consciousness and Cognition, 12, 695-707. doi:10.1016/S1053-8100(03)00052-7

Hegel, G. W. F. (1807). System der Wissenschaft. Erster Teil: Die Phänomenologie des Geistes, Josef Anton Goebhardt Verlag, Bamberg \& Würzburg.

Heidegger, M. (1927). Sein und Zeit, Max Niemeyer Verlag, Tübingen.

Helekar, S. A. (1999). On the possibility of universal neural coding of subjective experience. Consciousness \& Cognition, 8, 423-446. doi:10.1006/ccog.1998.0377

Herrmann C. S., Munk M. H., \& Engel A. K. (2004). Cognitive functions of gamma-band activity: Memory match and utilisation. Trends in Cognitive Sciences, 8, 347-355. doi:10.1016/j.tics.2004.06.006

Herzog, M. H., Esfeld, M., \& Gerstner, W. (2007). Consciousness and the smalll network argument. Neural Networks, 20, 1054-1056. 
doi:10.1016/j.neunet.2007.09.001

Holz E. M., Glennon M., Prendergast K., \& Sauseng P. (2010). Theta-gamma phase synchronization during memory matching in visual working memory. Neuroimage, 52, 326-336. doi:10.1016/j.neuroimage.2010.04.003

Jacobs, J., Kahana, M. J., Ekstrom, A. D., \& Fried, I. (2007). Brain oscillations control timing of single-neuron activity. Journal of Neuroscience, 27, 3839-3844. doi:10.1523/JNEUROSCI.4636-06.2007

Jaynes, J. (1990). The origin of consciousness in the breakdown of the bicameral mind. Boston, MA: Houghton-Mifflin.

John, E. R. (2002). The neurophysics of consciousness. Brain Research Reviews, 39, 1-28. doi:10.1016/S0165-0173(02)00142-X

Johnson, H. A., \& Buonomano, D. V. (2010). Neural dynamics of in vitro cortical networks reflects experienced temporal patterns. Nature Neuroscience, 13, 917-919. doi:10.1038/nn.2579

Jonides, J., Lewis, R. L., Nee, D. E., Lustig, C. A., Berman, M. G. \& Moore, K. S. (2008). The mind and brain of short-term memory. Annual Review of Psychology, 59, 193-224. doi:10.1146/annurev.psych.59.103006.093615

Kierkegaard, S. (1949, 1949). Traité du desespoir. Paris: Gallimard.

Kornhuber, H., \& Deecke, L. (1965). Hirnpotentialänderungen bei Willkurbewegungen und passiven Bewegungen des Menschen: Bereitschaftspotential und reafferente Potentiale. Pfluegers Archiv für die Gesamte Physiologie der Menschen und Tiere, 284, 1-17. doi:10.1007/BF00412364

Lamme, V. A. F. (2006). Towards a true neural stance in consciousness. Trends in Cognitive Sciences, 10, 494-501. doi:10.1016/j.tics.2006.09.001

Le Poidevin, R., \& MacBeath, M. (1993). The philosophy of time. Oxford: Oxford University Press.

Libet, B. (2004). Mind time. Cambridge: Harvard University Press.

Lisman, J. (2010). Working memory: The importance of theta and gamma oscillations. Current Biology, 20, 490-492. doi:10.1016/j.cub.2010.04.011

Lloyd, D. (2004). Radiant cool. Cambridge, MA: MIT Press.

Luo, H., \& Poeppel, D. (2007). Phase patterns of neuronal responses reliably discriminate speech in human auditory cortex. Neuron, 54, 1001-1010. doi:10.1016/j.neuron.2007.06.004

Maia, T. V., \& Cleeremans, A. (2005). Consciousness: Converging insights from connectivist modelling and neuroscience. Trends in Cognitive Sciences, 9, 397-404. doi:10.1016/j.tics.2005.06.016

Mathewson, K. E. et al. (2009). To see or not to see: Prestimulus alphaphase predicts visual awareness. Journal of Neuroscience, 29, 2725-2732. doi:10.1523/JNEUROSCI.3963-08.2009

Melloni, L., Molina, C., Pena, M., Torres, D., Singer, W., \& Rodriguez, E. (2007). Synchronization of neural activity across cortical areas correlates with conscious perception. Journal of Neuroscience, 27, 2858-2865. doi:10.1523/JNEUROSCI.4623-06.2007

Natsoulas, T. (1999). A rediscovery of presence. Journal of Mind \& Behavior, 20, 17-42.

Nyberg, L., Kim, A. S. N., Habib, R., Levine, B., \& Tulving, E. (2010). Consciousness of subjective time in the brain. Proceedings of the National Academy of Sciences of the USA, 107, 22356-22359. doi:10.1073/pnas.1016823108

Palva, J. M., Palva, S., \& Kaila, K. (2005). Phase synchrony among oscillations in the human cortex. Journal of Neuroscience, 25, 3962-3972. doi:10.1523/JNEUROSCI.4250-04.2005

Palva, S., \& Palva, J. M. (2007). New vistas for frequency band oscillations. Trends in Neurosciences, 30, 150-158. doi:10.1016/j.tins.2007.02.001

Piaget, J. (1967). La construction du réel chez l'enfant. Neuchätel: Delachaux et Niestlé.

Rosenthal, D. M. (2008). Consciousness and its function. Neuropsychologia, 46, 829-840. doi:10.1016/j.neuropsychologia.2007.11.012

Sarrazin, J. C., Giraudo, M. D., \& Pittenger, J. B. (2007). Tau and Kappa effects in physical space: The case of audition. Psychological Research, 71, 201-218. doi:10.1007/s00426-005-0019-1

Singer, W. (2009). Distributed processing and temporal codes in neuronal networks. Cognitive Neurodynamics, 3, 189-196. doi:10.1007/s11571-009-9087-z

Smythies, J. (2003). Space, time, and consciousness. Journal of Consciousness Studies, 10, 47-56.

Stein, A. von, Chiang, C., \& König, P. (2000). Top-down processing mediated by inter-areal synchrony. Proceedings of the National Academy of Sciences of the USA, 97, 14748-14753.

Taylor, J. G. (1998). Constructing the relational mind. Psyche, 4, 10. doi:10.1073/pnas.97.26.14748 